\title{
Household food insecurity, coping strategies, and happiness: The case of two public housing communities
}

\author{
Mesfin Bezuneh a $*$ and Zelealem Yiheyis ${ }^{b}$ \\ Clark Atlanta University
}

Submitted June 5, 2019 / Revised October 17 and November 15, 2019 / Accepted November 18, 2019 /

Published online May 15, 2020

Citation: Bezuneh, M., \& Yiheyis, Z. (2020). Household food insecurity, coping strategies, and happiness: The case of two public housing communities. Journal of Agriculture, Food Systems, and Community Development, 9(3), 215-226. https://doi.org/10.5304/jafscd.2020.093.018

Copyright (C) 2020 by the Authors. Published by the Lyson Center for Civic Agriculture and Food Systems. Open access under CC-BY license.

\begin{abstract}
Food insecurity continues to affect a significant number of U.S. households, even during periods of economic growth and prosperity. Household food insecurity in the U.S. is measured with the Food Security Core Survey Module, which reflects the importance of household financial resource constraint as the ultimate cause of food insecurity. While the module recognizes some of the strategies households employ to cope with food hardships, it hardly encompasses the salient strategies commonly used by low-income families. The purpose of this study is to identify the major strategies lowincome households employ to cope with their food insecurity, and to gain insight into the process they go through toward making ends meet and into how

a* Corresponding author: Mesfin Bezuneh, Department of Economics, Clark Atlanta University; 1547 Laurel Park Circle; Atlanta, GA 30314 USA; mbezuneh@,cau.edu

b Zelealem Yiheyis, Department of Economics, Clark Atlanta University.
\end{abstract}

the process may affect their sense of overall happiness. To this end, a survey instrument ${ }^{1}$ was developed and administered to low-income households in two public housing communities in Atlanta, Georgia. The results indicated that the majority of the sampled households, even those classified as food secure, report insufficiency of income to cover their monthly expenses. As a consequence, they employed a number of coping strategies to make ends meet. These included forgoing or delaying purchases of non-food items and borrowing or seeking help from friends and relatives. The study also found a mismatch between household self-assessment of their food conditions and food-security level classification. Despite the severity of coping strategies used,

\section{Funding Disclosure}

We are grateful to the U.S. Department of Agriculture Economic Research Service (USDA ERS), through agreement no. 43-3AEM-8-80044, for funding this research. The views expressed in this paper are those of the authors and not necessarily of the funding agency.

${ }^{1}$ The survey instrument it is available from the corresponding author upon request. 
some households reported overall happiness with their lives, although, for the majority, the results suggested a positive association between perceptions of food sufficiency and a sense of overall happiness.

\section{Keywords}

Household Food Security, Food Assistance, Temporary Assistance for Needy Families (TANF), Public Housing Communities, Atlanta, USDA Food Security Core Survey Module, Coping Strategies, Happiness

\section{Introduction}

In 1984, the President's Task Force on Food Assistance noted that despite the long period of economic growth and relatively low unemployment that characterized the American economy over the prior decade, food insufficiency and hunger had continued to affect certain segments of the population at the household and individual levels (Gundersen \& Ziliak, 2018; Nord \& Andrews, 2002; Olson, 1999; President's Task Force, 1994). The problem of food insufficiency still remains a thorny issue, even during periods of economic growth. For example, in 2018, 14.3 million households were food insecure at some point during the year (U.S. Department of Agriculture Economic Research Service [USDA ERS], 2019b). Some sectors of the population are more vulnerable than others. For example, $22.5 \%$ of African-American and $18.5 \%$ of Hispanic households were food insecure, higher than the national average of $12.3 \%$ (USDA ERS, 2019b). Because food insufficiency is recognized as posing long-lasting challenges to nutrition, health, and social policy, there has been growing interest among researchers at public and private institutions both to measure U.S. food insufficiency and to generate explanations (Bickel, Nord, Price, Hamilton, \& Cook, 2000; Carlson,
Andrews, \& Bickel, 1999; Gundersen \& Ziliak, 2018; Maxwell \& Smith, 1992; Olson, 1999; U.S. Department of Health \& Human Services \& USDA, 1993).

These efforts led to the development of the Food Security Core Survey Module (FSCSM), a standard method of measuring household food security in the U.S. and Canada (Bickel et al., 2000; Tarasuk \& Beaton, 1999; USDA ARS, 1998). The module, which has been included as a Food Security Supplement to the Current Population Survey of the Bureau of the Census since 1995, is designed with a view to "obtaining information on a variety of specific conditions, experiences, and behaviors that serve as indicators of the varying degrees of the severity of the condition" from household direct responses to a series of 18 questions (Bickel et al., 2000, p. 9). The questions reflect different levels of severity of household food insecurity ranging, for example, from worrying about running out of food (least severe) to skipping meals or going without food all day (most severe).

The responses to the survey questions are combined into a single measure, the household food security scale, which measures the extent of household food insecurity as perceived, experienced, and described by respondents. ${ }^{2}$ The scale classifies respondents into four categories, each representing a range of severity. Until 2006, the four categories were food secure, food insecure without hunger, food insecure with moderate hunger, and food insecure with severe hunger. The categories were renamed in 2006, with the assessment method remaining the same, to the following comparable ranges of food security: high food security, moderate food security, low food security, and very low food security. ${ }^{3}$

The survey instrument reflects and underscores the importance of household financial

\footnotetext{
2 The scale is not affected by hunger due to voluntary dieting or fasting, normally, since food insecurity and hunger are the result of lack of money or other relevant resources to obtain food, as implied by the 18 questions (Bickel et al., 2000).

3 The USDA Economics Research Service notes the comparability of the old and new labels: "High food security (old label=Food security): no reported indications of food-access problems or limitations . . Marginal food security (old label=Food security): one or two reported indications - typically of anxiety over food sufficiency or shortage of food in the house. Little or no indication of changes in diets or food intake... Low food security (old label=Food insecurity without bunger): reports of reduced quality, variety, or desirability of diet. Little or no indication of reduced food intake...Very low food security (old label=Food insecurity with bunger): Reports of multiple indications of disrupted eating patterns and reduced food intake" (USDA ERS, 2019a).
} 
resource constraints as the ultimate cause of food insecurity, and provides more comprehensive information about the nature, occurrence, and degree of food deprivation than can be determined through traditional income and poverty measures. Nonetheless, the FSCSM has some well-recognized limitations, one of which pertains to coping strategies. The food security scale recognizes some of the strategies that households employ to cope with their food hardships. ${ }^{4}$ However, it does not, for obvious reasons, encompass all of the major strategies commonly employed by low-income families. Households who somehow meet their basic food needs using coping strategies that are not included in the survey instruments could conceivably be classified as food secure. Their sense of insecurity would probably surface if references were made in the survey to other commonly used coping mechanisms. These coping mechanisms are likely to increase in variety and frequency for low-income families, all the more so as household income further decreases.

It is not uncommon for households at different income levels to use various money-saving and income-augmenting techniques in their efforts to meet their food needs (Hill \& Kauff, 2001; Bartfeld \& Collins, 2017). However, as Hill and Kauff (2001) have noted, for low-income families "often living to the proverbial edge, routine strategies can make the difference between whether or not they can make ends meet each month" (p. 18). Understanding the frequency and intensity of coping mechanisms in use not only helps test the validity of the standard food security scale among very low-income families but also informs policy interventions to the extent that household foodinsecurity status is understated by the standard survey instrument (Nord, Coleman-Jensen, Andrews, \& Carlson, 2010).

In light of the coping mechanisms employed, it is also worth investigating how households assess their food conditions and how that relates to their sense of overall happiness. Happiness is becoming increasingly important both as an end/policy target and, possibly, as a means for improving personal well-being and as a determinant of economic outcomes (Sen, 1985; Piekałkiewicz, 2017). It is to be expected, as Prime Minister Tshering Tobgay of Bhutan noted in his remarks at the Climate Change and Food Security panel of the 2017 World Government Summit in Dubai: "You can't be happy if you are hungry. Food security is fundamental to happiness" (Debusmann, 2017). It is worth exploring the link between perceptions of food sufficiency and happiness as expressed by respondents cognizant of the different conceptions, dimensions, manifestations, measures, and determinants of happiness and of the limitations that these aspects of happiness may impose. In our view, this study will fill a gap in the existing literature on food insecurity coping strategies and their effects on perception of happiness.

The purpose of this study is, therefore, to identify the strategies used by very low-income households to cope with their food insecurity and to gain insight into the process they must go through toward making ends meet. Moreover, the study seeks to explore the implications of the coping strategies and household self-assessment of food conditions for the relevance and validity of the standard food-security classification and for household sense of overall happiness. To this end, informed in part by the results reported by Hill and Kauff (2001), we developed a survey instrument which was administered to low-income households in two public housing communities in Atlanta, Georgia. The coping strategy survey was conducted in 2004, following a modified food security survey (FSCSM) which we administered to assess the relationship between food insecurity events and government food assistance programs in the two communities. ${ }^{5}$

The remainder of this paper is organized as follows. The second section provides an overview of the sample; the third section describes the income levels and sources of income of the respondents. The fourth section identifies and describes the strategies that households employ to meet their food needs. In the fifth section, we present the households' self-assessment of the

\footnotetext{
${ }^{4}$ For example, substituting for or relying on a few kinds of low-cost food (question \#5 of FSCSM).

${ }^{5}$ For a comparative study of food security conditions in the two communities, see Bezuneh and Yiheyis (2003).
} 
levels of satisfaction of their food needs and of their overall well-being. The sixth section summarizes the findings of the study and concludes with policy implications.

\section{The Study Sites and Basic Profile of the Sample}

The sites for this study were two public housing communities with low- and mixed-income households in Atlanta, Georgia. ${ }^{6}$ The low-income public housing community had 500 apartment units, of which 493 were occupied at the time of the survey. The community housed a total population of 1,201 , with an average age of 24 , half of them under 18 , and $65 \%$ female. Single heads of households constituted the overwhelming majority of the community $(97 \%)$. The annual household income averaged $\$ 7,449,{ }^{7}$ which was for a community with a mean family size of 2.4. Roughly one of three householders and more than a quarter of adults aged between 18 and 54 were unemployed.

Twenty-nine percent of households in the community had persons with disabilities, $30 \%$ received social security benefits (S.S.I.), and 21\% received temporary assistance for needy families (TANF).

At the time of the survey, the mixed-income community was home for 182 low-income households receiving housing subsidies. The total number of residents was 365, of whom 163 were children (45\%) and 264 female (72\%). Of household heads, $97 \%$ were single, and $50 \%$ were unemployed. Forty-six percent of adults between 18 and 54 years of age were unemployed. The mean family size was two, with an average household income of $\$ 11,493$. One in five households had persons with disabilities, and a lower proportion received SSI $(14 \%)$ and TANF (9\%).

The sample was randomly drawn from lowincome households residing in these two communities. Heads of households were interviewed in person in their homes. The sample size for the household food security survey was 322, which represented $48 \%$ of the households from the two communities at the time of the survey. The survey on coping strategies was conducted with 59 households who were available and willing to participate in the survey.

Table 1 presents the basic profile of the sample for the study of coping strategies. The family size in the sample ranged between one and eight, with only one household having eight members. The majority of the sampled households had at least two members, although the number of singlemember households was hardly negligible. Children were present in $58 \%$ of the families interviewed. Families with children were predominantly femaleheaded. Half of the household heads that provided

\section{Table 1. Basic Characteristics of the Coping Strategies Study Sample}

\begin{tabular}{|c|c|c|}
\hline \multirow[b]{2}{*}{ Characteristics } & \multicolumn{2}{|c|}{ Households } \\
\hline & Number & Percent \\
\hline \multicolumn{3}{|l|}{ Household size: } \\
\hline 1 member & 19 & $32.2 \%$ \\
\hline $2-3$ members & 27 & 45.8 \\
\hline $4-8$ members & 13 & 22.0 \\
\hline \multicolumn{3}{|l|}{ Family structure: } \\
\hline Households, no children & 34 & 57.6 \\
\hline Single parent (mother) & 24 & 40.7 \\
\hline Dual parent & 1 & 1.7 \\
\hline \multicolumn{3}{|l|}{ Household head education: } \\
\hline College or some college & 6 & 10.2 \\
\hline High school or some high school & 41 & 69.5 \\
\hline Less than high school or none & 10 & 16.9 \\
\hline Not disclosed & 2 & 3.4 \\
\hline \multicolumn{3}{|l|}{ Employed family members: } \\
\hline Two & 2 & 3.4 \\
\hline One & 15 & 25.4 \\
\hline None & 42 & 71.2 \\
\hline \multicolumn{3}{|l|}{ Family monthly income (US\$): } \\
\hline Less than $\$ 500$ & 16 & 27.1 \\
\hline$\$ 500-\$ 999$ & 41 & 69.5 \\
\hline$\$ 1,000-\$ 1,999$ & 1 & 1.7 \\
\hline Not disclosed & 1 & 1.7 \\
\hline \multicolumn{3}{|l|}{ Food security status: } \\
\hline Secure & 19 & 32.2 \\
\hline Insecure & 40 & 67.8 \\
\hline
\end{tabular}

Note: The status of employment is as reported or described by respondents. "Unemployed" here and in related discussions refers to the condition of not working, not necessarily in the sense of the standard or official definition of unemployment.

\footnotetext{
${ }^{6}$ The description of the study sites in this and the following paragraph is based on the demographics data summaries obtained from the management offices of the two communities.

7 All currencies are in US dollars.
} 
the relevant information had attained at least a high school education. For every ten households interviewed, three reported that at least one family member was employed during the 12 months prior to the interview period, with an average duration of employment of nine months. A majority of the coping strategies sample (68\%) was food insecure, as determined from the initial survey results previously described. This figure is considerably higher than the $52 \%$ found for the entire sample and roughly six times the national average $(11.9 \%)$ reported for 2004. For the same year, the food insecurity rate among the black, non-Hispanic segment of the population was $23.7 \%$, while the average for Georgia was $12.6 \%$, indicating a very high prevalence of food security in the study sites at the time. ${ }^{8}$

\section{Level and Sources of Income}

Of the 58 families who disclosed their incomes, all but one had a monthly household income of less than $\$ 1,000$. The major sources of income included government assistance, social security benefits, and employment. For every four households interviewed, at least one reported an income of less than $\$ 500$ per month. The self-reported income levels of the respondents clearly indicated that the sample households lived on meager incomes, which becomes more evident when reported family income is viewed relative to household size and the poverty threshold at the time. Thus, 14 of the 16 households $(87.5 \%)$ with a total monthly income of less than $\$ 500$ had two or more members. Likewise, more than half of the households with reported income between $\$ 500$ and $\$ 1,000$ had multiple members. A monthly income of more than $\$ 1,000$ was reported by only one household, which also had the largest family size (eight) in the sample. To place these data in perspective, in 2003 (the year of the survey) the weighted average poverty thresholds ranged from $\$ 9,573$ (for one person, unrelated individual), $\$ 18,810$ (a household with four members) to $\$ 31,589$ (for a household of eight members), indicating that all the self-reported income levels were far below the poverty line. ${ }^{9}$

For most of the respondents, there was little variation in the level of their incomes from month to month. The sources of their incomes included government assistance $(68 \%)$, social security benefits $(39 \%)$, employment income $(20 \%)$, child support $(7 \%)$, and workers' compensation $(1.7 \%)$. Roughly half of the surveyed families derived their incomes from more than one source. ${ }^{10}$ Among the 29 households that indicated multiple sources of income, 38\% identified social security benefits as the most important source, followed by the Supplemental Nutrition Assistance Program (SNAP), formerly known as food stamps (21\%), wages $(17 \%)$, and Supplemental Security Income (SSI) $(17 \%)$.

Only seven families (12\%) indicated wages as the only source of income. Most of them reported a monthly income of less than $\$ 1,000$. As previously noted, the majority of respondents received some type of government assistance in addition to their housing subsidy. The three most frequently identified types of government assistance received were-in order of frequency-TANF, SNAP, and WIC. At the time of the interview, the duration of respondent participation in government assistance programs ranged from two months to 33 years. The majority of the recipients had been on government assistance for more than four years. All the recipients felt that government assistance was either so important (43\%) or extremely important $(57 \%)$ in their family budget that it would have been tough or impossible to make ends meet without it. Of all the food-insecure households, $72 \%$ reported that they received government assistance.

The majority of respondents indicated that their income levels were so low that they were unable to cover their basic expenses each month (Table 2). This remained true even when the sample was dichotomized by certain attributes. Families with children reported income shortfall at

\footnotetext{
${ }^{8}$ USDA ERS, 2019b. The average food insecurity rate for Georgia spans 2004-2006.

${ }^{9}$ https://www2.census.gov/programs-surveys/cps/tables/time-series/historical-poverty-thresholds/thresh04.csv

${ }^{10}$ Figures in parentheses represent households (as a percentage of the sample) who identified the item in the list of their income sources.
} 
a higher rate than households with no children. Households with two or more adults experienced less severe income shortfall than their single-adult counterparts. Likewise, households whose source of income included wages were able to cover their expenses at a substantially higher rate than those with no employed members. Nearly all households below the monthly income level of $\$ 500$ reported that their expenses exceeded their incomes. The proportion was noticeably lower for households in the next higher income range.

As would be expected, ability to cover expenses was also correlated with household food security status. The percentage of foodsecure households that affirmed the sufficiency of income was more than three times that of food-insecure families. However, not all food-secure households had sufficient income relative to their expenses. In fact, the majority of them (63\%) did not. The fact that some households were classified as food secure while they were unable to cover expenses each month may partly reflect their priority to meet food needs while forgoing or deferring other purchases of goods or services.

\section{Household Coping Strategies}

Households coped with their food insecurity in several ways. For example, Maxwell (1995) identifies six short-term, food-based coping strategies mentioned by survey respondents and listed in increasing order of severity: Eating less preferred foods, limiting portion size, borrowing food or money to buy food, maternal buffering (a mother substantially limits her eating, usually for the sake of her very young children), skipping meals, and skipping eating for whole days (pp. 9-11). Some of these are reflected in the standard food security survey instrument. ${ }^{11}$ However, these coping strategies are only food-based, and they do not bring to the fore the efforts that households have to make to avoid the relatively more severe ones among them. More broadly, household coping strategies involve income-augmenting and costcutting measures. The survey instrument designed and administered for this study included questions that elicit information on these strategies. The results of the survey are summarized below, where the financial circumstances of households, the strategies they employ to make ends meet, and their overall well-being are described.

As stated, the majority of surveyed households that were food secure reported an inability to finance their monthly expenses. This suggests that these households employed different coping strate-

${ }^{11}$ For example, questions \#5-8 of the FSCSM. 
gies, not reflected in the standard food security survey instrument, in their attempts to meet their food needs. Given that the overwhelming majority of the respondents lived on insufficient incomes that fell short of needed expenses, it would be informative for policymakers, social workers, and other interested parties to learn how families in question got by. Respondents were asked about how they stretched their incomes to finance their basic monthly expenses. Their responses are summarized in Table 3, where the frequencies of the strategies employed are presented.

The most common strategy for making ends meet was to stretch the money they had by controlling expenses. This strategy was mentioned by $77 \%$ of the respondents. The second most frequently used method was borrowing from friends and relatives, which was reported by roughly two-thirds of the relevant sample. A sizeable number also sought help from different sources, including relatives, friends, and churches. They reported receiving donations such as canned food, cereals, clothing, and monetary assistance from individuals and community organizations. Households also attempted to make ends meet by prioritizing their expenses: deciding which bills to pay on time, which ones to defer, and which ones to pay partially. Rent, electric bills, food, and phone bills were frequently mentioned in the list of priority expense items.

In addition to money-saving techniques, some households sought out opportunities to supplement income received from the formal sources mentioned above. A quarter of the relevant sample reported having rendered different kinds of services to friends, relatives, and others in exchange for cash. These services included babysitting, hairbraiding, helping people move, doing yard work, and housekeeping. Some families went as far as pawning their belongings to cover certain expenses.

For the primary coping strategy, controlling expenses, respondents used a variety of techniques to limit their expenses (Table 4). The majority of

Table 3. List and Frequencies of Strategies Used to Make Ends Meet

\begin{tabular}{lcc}
\hline Coping Strategies & $\begin{array}{c}\text { Number of households } \\
\text { Mentioning the strategy }\end{array}$ & $\begin{array}{c}\text { Households mentioning } \\
\text { the strategy } \\
\text { (\% of relevant sample*) }\end{array}$ \\
\hline Controlling expenses & 41 & $77.4 \%$ \\
\hline Borrowed from friends and relatives & 34 & 64.2 \\
\hline Sought help from relatives, friends, and community organizations & 24 & 45.3 \\
\hline Prioritized monthly expenses & 20 & 37.7 \\
\hline Sought opportunity for cash & 13 & 24.5 \\
\hline Pawned belongings & 5 & 9.4 \\
\hline Other & 2 & 3.8 \\
\hline
\end{tabular}

*The relevant sample size is 53 , the number of respondents who indicated how they make ends meet.

Table 4. Coping Strategies: Control Household Expenses

\begin{tabular}{lcc}
\hline Ways of controlling expenses & $\begin{array}{c}\text { \# of households } \\
\text { mentioning } \\
\text { method }\end{array}$ & $\begin{array}{c}\text { Households } \\
\text { mentioning method } \\
\text { as \% of relevant } \\
\text { sample* }\end{array}$ \\
\hline Forego buying clothes and shoes, not buying expensive clothes and shoes & 24 & $58.5 \%$ \\
\hline Buy only necessities, cut down buying junk food, forego special treats, not going out & 9 & 22.0 \\
\hline Disconnect phone, cut back on phone calls & 7 & 17.1 \\
\hline Use less electricity & 6 & 14.6 \\
\hline Cut down food consumption in order to last for the month & 4 & 9.8 \\
\hline Other & 3 & 7.3 \\
\hline
\end{tabular}

*The relevant sample size is 41 , the number of respondents who indicated that they controlled expenses to make ends meet. 
the relevant sample controlled expenses by forgoing purchases of clothes and shoes; in some cases, even for children. Other cost-saving techniques families used each month included buying less junk food, foregoing special treats, not going out for entertainment, dispensing with phone services, using less electricity for light and air conditioning, cutting down on food consumption, and, generally, purchasing only very basic necessities.

It is clear from the forgoing that households in the study sample lived on very low incomes, and most of them were unable to cover basic expenses from month to month. They struggled to make ends meet using a variety of cost-cutting and money-making strategies.

\section{Food Needs Satisfaction and Overall Well- being: Household Self-Assessment} As discussed above, the kind and frequency of coping strategies employed indicate, by conventional measures and viewed from the perspective of outsiders, how vulnerable and precarious respondents' economic lives were. Facing such dire financial circumstances, how do families perceive and characterize their food conditions and their overall well-being? This line of inquiry is intended to complement the standard food security analysis as it sheds additional insight into how respondents self-assess their views of their nutrition and overall life conditions, and how these two might be related.

Tables 5 and 6 record household selfassessments of how satisfied they were in meeting their food needs and how happy they were with their lives as a whole, on a four-part scale ranging from not at all satisfied (not at all happy) to very satisfied (very happy). Twenty-two percent of the respondents felt that they were very satisfied with meeting their food needs. Twice as many described their food situation as quite satisfactory; thus, $68 \%$ of the sampled households were quite or very satisfied with their food situation. In contrast, as reported above, the same percentage $(68 \%)$ of the sample was classified as food insecure based on the standard scale of food security. This divergence may partly reflect the low threshold of expectations that respondents used to evaluate their food needs satisfaction, given their living conditions and without necessarily taking into account the process involved in reaching the threshold through the

Table 5. Levels of Food Needs Satisfaction and Overall Happiness

\begin{tabular}{lcccc}
\hline & \multicolumn{2}{c}{$\begin{array}{c}\text { Satisfaction with respect to food needs } \\
\text { (Households) }\end{array}$} & $\begin{array}{c}\text { Happiness with respect to life in general } \\
\text { (Households) }\end{array}$ \\
\cline { 2 - 5 } Level of satisfaction/happiness & Number & Percent & Number & Percent \\
\hline Very satisfied/happy & 13 & $22.0 \%$ & 16 & $27.1 \%$ \\
\hline Quite satisfied/happy & 27 & 45.8 & 30 & 50.8 \\
\hline Not very satisfied/happy & 18 & 30.5 & 12 & 20.3 \\
\hline Not at all satisfied/happy & 1 & 1.7 & 1 & 1.7 \\
\hline Total & 59 & 100.0 & 59 & 100 \\
\hline
\end{tabular}

Table 6. Cross Tabulation of Levels of Food Needs Satisfaction and Overall Happiness

\begin{tabular}{|c|c|c|c|c|c|c|}
\hline \multirow{2}{*}{\multicolumn{2}{|c|}{ Level of satisfaction and level of happiness }} & \multicolumn{4}{|c|}{ Level of happiness with life in general } & \multirow[b]{2}{*}{ Total } \\
\hline & & Very happy & Quite happy & Not very happy & Not at all happy & \\
\hline \multirow{5}{*}{$\begin{array}{c}\text { Level of } \\
\text { satisfaction } \\
\text { with food needs }\end{array}$} & Very Satisfied & 9 & 4 & 0 & 0 & 13 \\
\hline & Quite satisfied & 5 & 16 & 5 & 1 & 27 \\
\hline & Not very satisfied & 2 & 10 & 6 & 0 & 18 \\
\hline & Not at all satisfied & 0 & 0 & 1 & 0 & 1 \\
\hline & Total & 16 & 30 & 12 & 1 & 59 \\
\hline
\end{tabular}


various coping strategies discussed above.

It is worth noting that more than $60 \%$ of the respondents who were satisfied with respect to meeting their food needs participated in SNAP or WIC programs. However, not all recipients of food stamps rated their food condition as satisfactory. More than a quarter of participants receiving food benefits reported that their food needs were unmet. The corresponding figure for non-recipients was higher, at 38\%. Taken together, these figures suggest that participation in SNAP or WIC programs seemed to have exerted some impact on household sense of satisfaction with respect to their food needs.

Next, we report how respondents viewed their overall subjective well-being and how this rating is related to their assessment of their food conditions. More than three-quarters of the sample felt that they were very happy or quite happy overall. More people expressed overall happiness in their lives $(78 \%)$ than satisfaction with food needs (68\%). A cross-tabulation of the two indicators (Table 6) shows that 34 families (58\%) felt that their food condition was satisfactory and that they were happy. In contrast, seven households $(12 \%)$ expressed dissatisfaction with their food condition and unhappiness about their lives in general. Contrary to what might be considered conventional wisdom, two families $(3 \%)$ were dissatisfied with respect to meeting their food needs, and yet they characterized their life experiences as very happy, which may reflect what Sen (1983) described as a "cheerful disposition" that is not directly bound to possession of material resources and to one's living standard (p. 160). On the other hand, six (10\%) of the respondents were generally unhappy, although they were quite satisfied with their food situation.

Examining the extremes of respondent selfassessments discloses that none of the respondents who were very satisfied with their food condition reported unhappiness in their lives. Likewise, no household that was least satisfied with its food condition rated its overall happiness favorably. Curiously, no household ranked its condition at the bottom tier of the satisfaction/happiness spectrum on both counts. Taken together, the self-assessment results suggest that while a sense of satisfaction with respect to food sufficiency does not ensure overall happiness, it may contribute to it (Feeny, McDonald, \& Posso, 2014; White, Fernandez, \& Jha, 2016). To put it differently, the findings seem to suggest that the ability to meet food needs is one of the contributing factors to overall wellbeing and happiness. This is consistent with the findings reported in empirical studies of the determinants of happiness, which also include noneconomic factors such as leisure consumption, social connectedness/relationships, mental and physical health, and work-life balance (Clark, Flèche, Layard, Powdthavee, \& Ward, 2017; DeLeire \& Kalil, 2010; Graham, 2009; Layard, 2005; Li, 2016).

\section{Summary and Conclusions}

One of the well-known shortcomings of the standard food security scale pertains to coping strategies. The scale does not reflect the major strategies commonly employed by low-income families. Households who somehow manage to meet their basic food needs using coping strategies not included in the scale could conceivably be classified as food secure. Their basic sense of insecurity would probably surface if inquiry encompassed other commonly used coping strategies in addition to those included in the standard survey instrument. For example, $42 \%$ of the sampled households that were classified as food secure in the standard foodsecurity scale reported controlling nonfood expenses as one of their coping strategies.

Accordingly, a separate coping strategy survey instrument was designed and administered. The results indicate that the overwhelming majority of the respondents reported inability to finance their basic expenses each month. Households employed a variety of cost-saving and money-making strategies in order to make ends meet. These included controlling expenses; borrowing from friends and relatives; seeking help from friends, relatives, and churches; prioritizing expenses; and seeking out opportunities to augment household incomes. Despite their dire financial circumstances, but partly because of the coping strategies they employ, roughly two-thirds of the respondents were satisfied with respect to meeting their food needs. Despite the financial hardships and challenges they face each month, more than three-quarters of the 
sample expressed overall happiness.

The results of our study should, however, be interpreted with caution, partly because of the sample size on which they are based. A sample size of 59 is small, although hardly atypical for ethnographic studies involving in-depth, face-to-face interviews, as in the present study. In addition, the study uses descriptive statistics, focusing on the portrayal of household coping strategies and perceptions rather than on hypothesis testing. Indeed, a larger sample size and a quantitative analysis involving statistical tests would have enabled us to draw stronger conclusions. Despite these limitations, the reported findings are suggestive, and from them several tentative conclusions with policy implications could be drawn. First, despite receipt of government assistance, a substantial percentage of the sampled households remained food insecure. This may be partly due to the inadequacy of the amount and/or the ineffectiveness of the type of assistance received. In the light of further investigation of this particular issue, increasing the amount and/or accordingly tailoring the type of assistance provided would be an appropriate policy measure to enhance the food security conditions of the households in question. More specifically, the results of this study may inform the process of decision making for relevant departments at the state and federal government levels concerning the amount, type, and timing of support that needs to be provided to low and no-income households.

Second, low-income families can be classified as food secure, and yet still be unable to cover basic expenses each month and have to continually use a variety of coping mechanisms to meet their basic needs. This calls for appropriately modifying the standard food security survey instrument to reflect the variety of coping strategies that lowincome households typically employ. To do so would enhance the relevance of the survey for very low-income populations, thus minimizing the underestimation of food insecurity among them, and thereby perhaps inducing policy interventions that would otherwise fail to take into account the realities with which low-income households cope.

Finally, a sense of satisfaction with respect to food sufficiency positively contributes to a sense of overall happiness and welfare, although people could still be happy despite food insufficiency, thanks to their overall positive outlook on life and being content in other aspects of their lives. Certainly, overall happiness is not only an end but also a means for increasing personal and family welfare on different dimensions. The ability to meet food needs is one of the many manifestations of, and contributory factors to, overall well-being and happiness, rendering food-security enhancing policies and measures all the more consequential. Future research based on the observational, ethnographic method and larger sample sizes would undoubtedly increase our understanding of household coping strategies when faced with food insecurity, and inform strategies to formulate appropriate policies.

\section{Acknowledgments}

We thank Ann Vanderman (U.S. Department of Agriculture Economic Research Service), Glenn Ames (University of Georgia), Frank Dadzie (Clark Atlanta University), and the anonymous reviewers of this journal for their helpful comments and suggestions.

\section{References}

Bartfeld, J., \& Collins, J. M. (2017). Food insecurity, financial shocks, and financial coping strategies among households with elementary school children in Wisconsin. Journal of Consumer Affairs, 51(3), 519-548. https://doi.org/10.1111/joca.12162

Bezuneh, M., \& Yiheyis, Z. (2003). Assessing the relationship between food insecurity events and food assistance programs in two different public housing communities (Final Report). Atlanta: Clark Atlanta University. Retrieved from https://srdc.msstate.edu/ridge/archive/files/recipients/01_bezuneh_final.pdf

Bickel, G., Nord, M., Price, C., Hamilton, W., \& Cook, J. (2000). Guide to measuring housebold food security (Revised). Alexandria, VA: U.S. Department of Agriculture, Food and Nutrition Service, Office of Analysis, Nutrition, and Evaluation. Retrieved from https://www.fns.usda.gov/guide-measuring-household-food-security-revised-2000 
Carlson, S. J., Andrews, M. S., \& Bickel, G. W. (1999). Measuring food insecurity and hunger in the United States: Development of a national benchmark measure and prevalence estimates. The Journal of Nutrition, 129(2), 510S-516S. https://doi.org/10.1093/jn/129.2.510S

Clark, A. E., Flèche, S., Layard, R., Powdthavee, N., \& Ward, G. (2017). The key determinants of happiness and misery (CEP Discussion Paper No. 1485). London: London School of Economics, Centre for Economic Performance. Retrieved from http://eprints.lse.ac.uk/83622/

Debusmann, B. (2017, February 13). Climate change and food security inextricably linked. The Khaleej Times. https://www.khaleejtimes.com/news/government/climate-change-and-food-security-inextricably-linked

DeLeire, T., \& Kalil, A. (2010). Does consumption buy happiness? Evidence from the United States. International Review of Economics, 57(2), 163-176. https://doi.org/10.1007/s12232-010-0093-6

Feeny, S., McDonald, L., \& Posso, A. (2014). Are poor people less happy? Findings from Melanesia. World Development, 64, 448-459. https://doi.org/10.1016/j.worlddev.2014.06.022

Graham, C. (2009). Happiness around the world: The paradox of happy peasants and miserable millionaires. New York: Oxford University Press.

Gundersen, C., \& Ziliak, J. P. (2018). Food insecurity research in the United States: Where we have been and where we need to go. Applied Economic Perspectives and Policy, 40(1), 119-135. https://doi.org/10.1093/aepp/ppx058

Hill, H., \& Kauff, J. (2001). Living on little: Case studies of Iowa families with very low incomes. Washington, D.C.: Mathematica Policy Research. Retrieved from https://aspe.hhs.gov/pdf-report/living-little-case-studies-iowa-families-very-low-incomes

Layard, R. (2005). Happiness: Lessons from a new science. London: Allen Lane Penguin Group.

Li, J. (2016). Why economic growth did not translate into increased happiness: Preliminary results of a multilevel modeling of happiness in China. Social Indicators Research, 128, 241-263. https://doi.org/10.1007/s11205-015-1028-0

Maxwell, D. G. (1995). Measuring food insecurity: The frequency and severity of "coping strategies" (FCND Discussion Paper No. 8). Washington, DC: International Food Policy Research Institute, Food Consumption and Nutrition Division.

Maxwell, S., \& Smith, M. (1992). Household food security: A conceptual review. In S. Maxwell \& T. R. Frankenberger (Eds.), Household food security: Concepts, indicators, measurements. A technical review (pp. 1-72). New York \& Rome: United Nations Children's Fund \& International Fund for Agricultural Development. Retrieved from http://socialprotection.gov.bd/wp-content/uploads/2017/06/IFAD-HH-Food-Security-Full-Document.pdf

Nord, M., \& Andrews, M. (2002). Reducing food insecurity in the United States: Assessing progress toward a national objective (Food Assistance and Nutrition Research Report No. 26-2). Washington, DC: U.S. Department of Agriculture, Economic Research Service. Retrieved from https://naldc.nal.usda.gov/download/36551/PDF

Nord, M., Coleman-Jensen, A., Andrews, M., \& Carlson, S. (2010). Household food security in the United States, 2009 (ERS Report No. 108). Retrieved from https://www.ers.usda.gov/webdocs/publications/44776/7024 err108 1 .pdf?v=41056

Olson, C. M. (1999). Nutrition and health outcomes associated with food insecurity and hunger. The Journal of Nutrition, 129(2), 521S-524S. https://doi.org/10.1093/in/129.2.521S

Piekałkiewicz, M. (2017). Why do economists study happiness? The Economic and Labour Relations Review, 28 (3), 361-377. https://doi.org/10.1177/1035304617717130

President's Task Force on Food Assistance. (1984). Report of the President's Task Force on Food Assistance. Retrieved from https://www.worldcat.org/title/report-of-the-presidents-task-force-on-food-assistance/oclc/11203522

Sen, A. (1983). Poor, relatively speaking. Oxford Economic Papers, 35(2), 153-169. https://doi.org/10.1093/oxfordjournals.oep.a041587

Sen, A. (1985). Commodities and capabilities. Amsterdam: Elsevier.

Tarasuk, V. S., \& Beaton, G. H. (1999). Household food insecurity and hunger among families using food banks. Canadian Journal of Public Health, 90, 109-113. https://doi.org/10.1007/BF03404112

U.S. Department of Agriculture (USDA) Agricultural Research Service (ARS). (1998). United States USD A continuing survey of food intake by individuals/Diet and health knowledge survey 1994-1996 and 1998. Washington, DC: USDA ARS. Retrieved from https://www.ars.usda.gov/northeast-area/beltsville-md-bhnrc/beltsville-human-nutrition-researchcenter/food-surveys-research-group/docs/past-surveys/ 
USDA Economic Research Service (ERS). (2019a). Definitions of food security. Retrieved from https://www.ers.usda.gov/topics/food-nutrition-assistance/food-security-in-the-us/definitions-of-foodsecurity.aspx

USDA ERS. (2019b). Food security in the U.S. Retrieved from https://www.ers.usda.gov/topics/food-nutritionassistance/food-security-in-the-us/interactive-charts-and-highlights/

U.S. Department of Health and Human Services \& USDA. (1993, June 11). Ten-year comprehensive plans for the national nutrition monitoring and related research program (Federal Register). 58 FR 32752-32806.

White, S. C., Fernandez, A., \& Jha, S. (2016). Beyond the grumpy rich man and the happy peasant: Mixed methods and the impact of food security on subjective dimensions of well-being in India. Oxford Development Studies, 44(3), 332-348. https://doi.org/10.1080/13600818.2015.1120278 